\title{
Research on Location of Cold Chain Logistics Distribution Center Based on "Internet +"
}

\author{
Junkai Luan* \\ School of management \\ Wuhan University of science and technology \\ Wuhan, China \\ luanjunkai@vip.qq.com
}

\author{
Kailing Pan \\ School of management \\ Wuhan University of science and technology \\ Wuhan, China \\ pank10122@163.com
}

\begin{abstract}
The purpose of this paper is to through the " Internet $+"$ environment, reasonable cold-chain logistics distribution center location selection, ensure the efficient operation of logistics system, to reduce the comprehensive cost of the logistics enterprise and guarantee fresh fast, with good quality product to the consumer sector. Consider fresh product qualities, to combine theory and empirical, cold-chain logistics distribution center location optimization model is established, through the immune optimization algorithm of the model, to determine the optimal scheme, the algorithm by using the model cities in hubei province cold-chain logistics distribution center location analysis, to verify the effectiveness of the model algorithm. The cold-chain logistics distribution center location problem with "Internet +", at the same time, considering the cost factor, to adapt to the direction of the cold chain logistics industry development in our country, the cold chain logistics distribution center location problem provides a new decision method and basis.
\end{abstract}

Keywords-"Internet +"; cold chain logistics; distribution center site; Immune optimization

\section{INTRODUCTION}

Under the wave of "Internet +", as the income growth and consumption upgrade, urban and rural residents for safety, health, the pursuit of high quality of life have further, increased the demand for fresh food and medical products, provides opportunities for the development of cold chain logistics. In April 2017, issued by the general office of the state council "about speed up the development of cold chain logistics safeguard food safety's opinions on promoting consumption upgrading", clear the goals and tasks of cold chain logistics development and specific measures, created better conditions for the development of cold chain logistics. According to statistics from the China federation of the cold chain, the demand for the national cold chain logistics market reached 220 billion yuan in 2016, an increase of $22.3 \%$ year on year. In spending power and for the improving of the food safety value degree, policy support continue to overweight, fresh superposition of multiple factors, such as electric business rise, cold chain logistics will usher in the golden age of rapid development.

At present, the research on the site selection of cold chain distribution center at home and abroad mainly aims at perfecting the cold chain logistics system, reducing the transport loss, shortening the delivery time and improving the efficiency of the cold chain logistics. Beresnev v. 1. and MelNikov A A.[1](2011) consider the problem of facility location in A competitive environment, transform the problem into a second-level integer programming problem, and the final result is obtained by local search algorithm. Guan fei, zhang qiang [2](2013), in consideration of fuzzy environment, such as the minimum cost and highest service level, the fuzzy multi-target location model can be solved by particle swarm algorithm. Ozgen d. and Gulsun B.[3] (2014) solved the dual target location model by combining linear programming and fuzzy analytic hierarchy process. Wei fei etc.[4] (2015) solved the minimum integer programming model by using the immune cloning algorithm to predict the demand. Yuan Qun, zuo yi[5](2016) at the same time considering multiple constraints, building complex combination optimization model the fusion of genetic algorithm and tabu search algorithm, the improved crossover operator and greedy algorithm of hybrid genetic algorithm to solve the model.

In the context of "Internet $+"$, this paper establishes a selection optimization model of cold chain logistics distribution center, and determines the optimal location plan by using the immune optimization algorithm to solve the model.

\section{THE DISTRIBUTION CHARACTERISTICS OF "INTERNET +" FRESH PRODUCTS}

The distribution of fresh products in the "Internet +" environment needs to reflect the multiple attributes of informatization, modernization and socialization [6]. Therefore, the cold chain logistics distribution of fresh products under the "Internet +" environment has the following obvious features: first, virtualization. Fresh products distribution can use based on the Internet to construct virtual space real-time monitoring on logistics activities, each shipping reasonable cohesion, improve the efficiency of distribution, reducing distribution costs. Second, informationization. The development of Internet speeds up the efficiency of information transmission and reduces the circulation cost of information. The application of information technology in the field of cold chain logistics leads to major changes in the development of cold chain logistics. The commercialization, code, standardization and digitization 
of cold chain logistics information provide reliable guarantee for fast and efficient distribution. Third, automation. The automated cold-chain logistics distribution system can improve the efficiency of labor production, reduce the error of operation links, expand the operation scale, and exert the scale effect. Fourth, networking. Through the cold chain logistics distribution network system to strengthen the relationship between cold chain logistics distribution center and upstream suppliers and downstream customers, realize the organic integration of capital flow, information flow and logistics. Fifthly, flexibility. By supply and demand information, storage information collected information, traffic information, such as information, the organization and implementation of flexible operations, meet the parties optimal allocation of resources, to achieve maximum customer satisfaction.

\section{PROBLEM ANALYSIS}

Cold chain logistics distribution center play a key role in the whole logistics network, reasonable cold chain distribution center location can ensure the effective operation of logistics system, at the same time direct influence on cold chain logistics activities. In the construction of cold chain logistics distribution center location optimization model, the minimum total cost as the goal, the total cost of the cold-chain logistics distribution center construction costs, transportation costs, distribution costs, operating costs, the cost of damage.

\section{A. Modeling assumption}

In order to simplify the complex modeling process and make effective measurement, the following assumptions are made from both theoretical and feasibility.

(1) One demand point and only one supply point;

(2) A supply point can supply multiple demand points simultaneously;

(3) The transport cost is in direct proportion to the amount of transport and the distance of transport;

(4) The speed in the distribution process is known, for a constant, regardless of the difference between different sections;

(5) The demand of each demand point is a single product requirement and the quantity demanded is known;

(6) The scale of the cold chain logistics distribution center can meet the demand point and can guarantee the supply of demand in the range of radiation.

\section{B. Symbol description}

$a$ : Unit freight cost;

$I, J, K$ : Supply point, cold chain logistics distribution center and demand point quantity;

$x_{i j}$ : Supply point I to cold chain logistics distribution

logistics center $\mathrm{j}$

$x_{j k}$ : Flow from the cold chain logistics distribution center $\mathrm{j}$

to the demand point $\mathrm{k}$;

$d_{i j}$ : Transport distance from supply point to cold chain

logistics distribution logistics center; $d_{j k}$ : The distribution distance from cold chain logistics distribution center to demand point;

$h_{1} 、 h_{2}$ : Scale effect index; $Y_{j}: 0-1$ integer;

$v$ : Average delivery rate; $\theta$ : Decay rate;

$\varepsilon$ : Cost of unit damage;

$\delta$ : A decline in market demand caused by a decrease in freshness;

$\partial$ : The unit transportation rate of cold chain logistics distribution center;

$w_{j}$ : Unit operating cost; $p$ : Operation scale effect constant;

$S$ : The storage and distribution capacity of each logistics center is limited;

$Z_{\mathrm{k}}$ : The market's original demand;

$D$ : The number of restrictions on the distribution center of cold chain logistics;

\section{Cost analysis}

The total cost of the selection of cold chain distribution center considered in this paper includes transportation cost, distribution cost, cost of goods loss, cost of loss and operation cost.

Cold-chain logistics distribution center transport costs include the cost of transportation from supplier to the cold chain distribution center and from the cold chain distribution center to demand point distribution costs, transport mainly road, so the main consideration of highway transportation cost. According to wang min [7], the transportation costs and distribution costs under consideration of economies of scale are:

Transportation cost: $C_{Y}=\sum_{\mathrm{i}=1}^{I} \sum_{\mathrm{j}=1}^{J}\left(\mathrm{ax}_{\mathrm{ij}}{ }^{\mathrm{h}_{1}} \mathrm{~d}_{\mathrm{ij}}{ }^{\mathrm{h}_{2}} \mathrm{Y}_{\mathrm{j}}\right)$

Distribution cost: $C_{\mathrm{P}}=\sum_{\mathrm{j}=1}^{J} \sum_{\mathrm{k}=1}^{K}\left(\mathrm{ax}_{\mathrm{jk}}{ }^{\mathrm{h}_{1}} \mathrm{~d}_{\mathrm{jk}}{ }^{\mathrm{h}_{2}} Y_{\mathrm{j}}\right)$

This article is based on fresh degree, on the basis of considering the Meng Guanghua [8] study of damage in the process of cold chain transport costs and zhang jian, $\mathrm{Fu}$ Shaochuan [9] study freshness falling demand for downstream affect the cost of the damage caused by:

Cost of damage:

$C_{H}=\varepsilon \sum_{i=1}^{I} \sum_{\mathrm{j}=1}^{\mathrm{J}} \mathrm{x}_{\mathrm{ij}}\left(1-\mathrm{e}^{-\theta \frac{\mathrm{d}_{\mathrm{ij}} \mathrm{Y}_{\mathrm{j}}}{\mathrm{v}}}\right)+\varepsilon \sum_{j=1}^{J} \sum_{k=1}^{K} \mathrm{x}_{\mathrm{jk}}\left(1-\mathrm{e}^{-\theta \frac{\mathrm{d}_{\mathrm{jk}} \mathrm{Y}_{\mathrm{j}}}{\mathrm{v}}}\right)$

Cost of loss:

$C_{S}=100 \delta \partial \sum_{\mathrm{i}=1}^{I} \sum_{\mathrm{j}=1}^{J} \sum_{\mathrm{k}=1}^{K}\left\{\mathrm{x}_{\mathrm{ij}}\left(1-\mathrm{e}^{-\theta \frac{\mathrm{d}_{\mathrm{ij}} \mathrm{Y}_{\mathrm{j}}}{\mathrm{v}}}\right)+\mathrm{x}_{\mathrm{jk}}\left(1-\mathrm{e}^{-\theta \frac{\mathrm{d}_{\mathrm{jk}} \mathrm{Y}_{\mathrm{j}}}{\mathrm{v}}}\right)\right\}$

Cold-chain logistics distribution center operating costs as part of the total cost of Ye Xiangkui [10] by nonlinear function to describe the operating expenses function as shown in figure1, because of the influence of the scale effect, with the larger scale of the distribution center, the change of operating costs should gradually become smaller. 
Operating costs: $C_{\mathrm{y}}=W_{\mathrm{j}}\left(\sum_{i=1}^{I} \sum_{j=1}^{J} x_{i j}\right)^{p}$

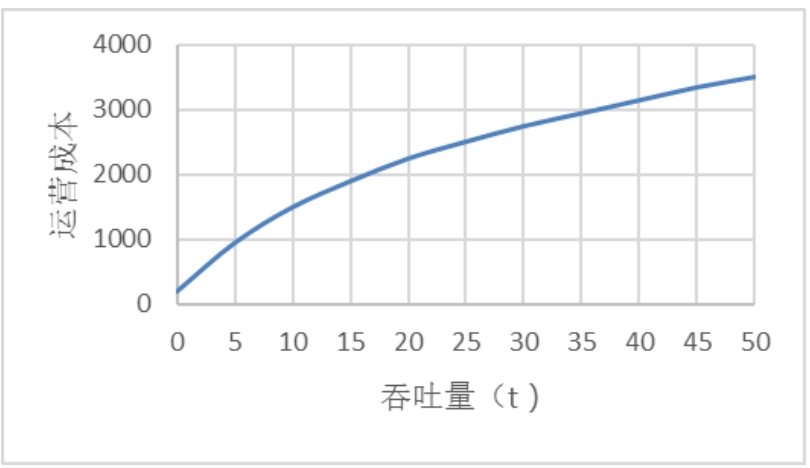

Fig. 1 Operation cost function

\section{Model}

Through the above analysis of cold chain logistics distribution center location model:

$\operatorname{Min} C=\sum_{\mathrm{i}=1}^{I} \sum_{\mathrm{j}=1}^{J}\left(\mathrm{ax}_{\mathrm{ij}}{ }_{\mathrm{h}_{1}} \mathrm{~d}_{\mathrm{ij}}{ }_{\mathrm{h}_{2}} \mathrm{Y}_{\mathrm{j}}\right)+\sum_{\mathrm{j}=1}^{J} \sum_{\mathrm{k}=1}^{K}\left(\mathrm{ax}_{\mathrm{jk}}{ }^{\mathrm{h}_{1}} \mathrm{~d}_{\mathrm{jk}}{ }_{\mathrm{h}_{2}} Y_{\mathrm{j}}\right)$

$+\varepsilon \sum_{i=1}^{I} \sum_{\mathrm{j}=1}^{\mathrm{J}} \mathrm{x}_{\mathrm{ij}}\left(1-\mathrm{e}^{-\theta \frac{\mathrm{d}_{\mathrm{ij}} \mathrm{Y}_{\mathrm{j}}}{\mathrm{v}}}\right)+\varepsilon \sum_{j=1}^{J} \sum_{k=1}^{K} \mathrm{x}_{\mathrm{jk}}\left(1-\mathrm{e}^{-\theta \frac{\mathrm{d}_{\mathrm{jk}} \mathrm{Y}_{\mathrm{j}}}{\mathrm{v}}}\right)$

$+100 \delta \partial \sum_{\mathrm{i}=1}^{I} \sum_{\mathrm{j}=1}^{J} \sum_{\mathrm{k}=1}^{K}\left\{\mathrm{x}_{\mathrm{ij}}\left(1-\mathrm{e}^{-\theta \frac{\mathrm{d}_{\mathrm{ij}} \mathrm{Y}_{\mathrm{j}}}{\mathrm{v}}}\right)+\mathrm{x}_{\mathrm{jk}}\left(1-\mathrm{e}^{-\theta \frac{\mathrm{d}_{\mathrm{jk}} \mathrm{Y}_{\mathrm{j}}}{\mathrm{v}}}\right)\right\}$

$+W_{\mathrm{j}}\left(\sum_{i=1}^{I} \sum_{j=1}^{J} x_{i j}\right)^{p}$

$\sum_{i=1}^{I} \sum_{j=1}^{J} x_{i j}=\sum_{j=1}^{J} \sum_{k=1}^{K} x_{j k}=\sum_{k=1}^{K} Z_{k}$

$\sum_{i=1}^{I} Y_{j} x_{i j} \leq S$

$\sum_{j=1}^{J} Y_{j}=D$

$\sum_{i=1}^{I} x_{i j} \leq M Y_{j}$

$\sum_{k=1}^{K} x_{j k} \leq M Y_{j}$

$x_{i j}, x_{j k} \geq 0$

(3-1) means that the purchase quantity of the cold chain logistics distribution center is the same as the quantity of incoming transportation; (3-2) means that the storage capacity of cold chain logistics distribution center meets the purchase requirement; (3-3) the quantity of cold chain logistics distribution center; (3-4), (3-5) means that the cold chain logistics distribution center is not selected at $\mathrm{j}$ point, and its input output is zero; (3-6) means that the purchasing quantity and transportation quantity of cold chain logistics distribution center are positive.

\section{E. Immunological optimization algorithm}

The immune algorithm is a new method to simulate the antigen antibody of biological immune system. Has a fast convergence speed and global optimization ability, etc, in view of the characteristic agricultural products distribution center's site selection analysis, to generate the initial antibody, use the diversity of the immune system and maintain the mechanism to ensure that the groups of diversity, overcome the "premature" in the process of multimodal function optimization problems. The flow chart of the immune optimization algorithm is shown in figure 2.

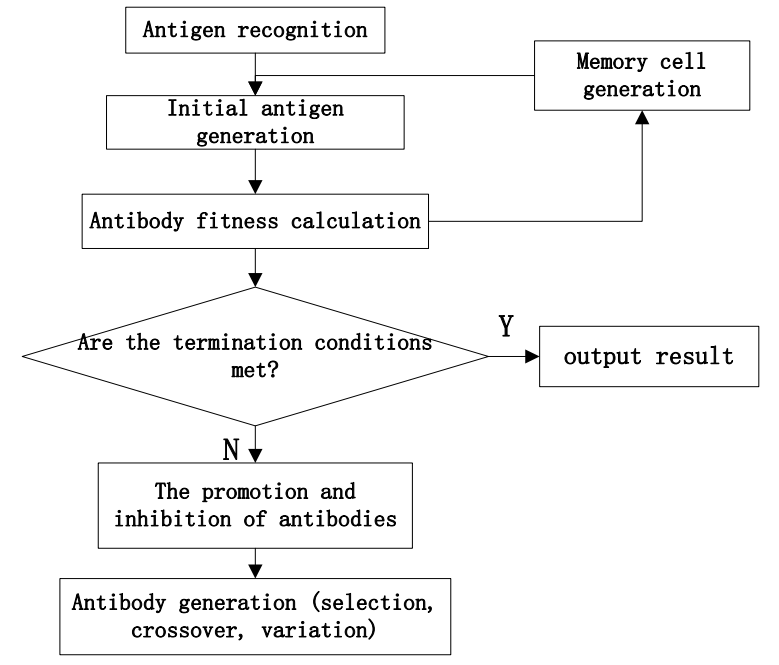

Fig. 2 Flow chart of immune optimization algorithm

\section{NUMERICAL EXAMPLE}

$\mathrm{H}$ logistics enterprise to decide in hubei province set up a number of cold chain logistics distribution center, to adapt to the "Internet + " environment of fresh agricultural products purchasing, processing, distribution and other business, so as to meet the needs of enterprise business development and market demand. The location coordinates of each demand point and the demand for each demand point are shown in table 1 .

TABLE I DEMAND POINT COORDINATES AND AGRICULTURAL PRODUCTS IN HUBEI PROVINCE

\begin{tabular}{|c|c|c|}
\hline Number (city) & $\begin{array}{c}\text { Demand point } \\
\text { coordinates }\end{array}$ & $\begin{array}{c}\text { Quantity } \\
\text { demanded }\end{array}$ \\
\hline 1wuhan & $(30.35,114.17)$ & 90 \\
\hline 2huangshi & $(30.12,115.06)$ & 25 \\
\hline 3 shiyan & $(32.40,110.47)$ & 33 \\
\hline 4yichang & $(30.42,111.17)$ & 41 \\
\hline 5xiangyang & $(32.02,112.08)$ & 55 \\
\hline 6ezhou & $(30.23,114.52)$ & 14 \\
\hline 7jingmen & $(31.02,112.12)$ & 29 \\
\hline 8xiaogan & $(30.56,113.54)$ & 48 \\
\hline 9jingzhou & $(30.18,112.16)$ & 57 \\
\hline 10huanggang & $(30.27,114.52)$ & 62 \\
\hline 11xianning & $(29.53,114.17)$ & 25 \\
\hline 12suizhou & $(31.42,113.22)$ & 22 \\
\hline 13enshi & $(30.16,109.29)$ & 33 \\
\hline 14xiantao & $(30.22,113.27)$ & 12 \\
\hline 15qianjiang & $(30.26,112.53)$ & 9 \\
\hline 16tianmen & $(30.67,113.17)$ & 14 \\
\hline 17shennongjia & $(31.60,110.50)$ & 8 \\
\hline
\end{tabular}


Through the consideration of the distribution of market demand and the reasonable layout of the overall planning, through preliminary screening, three of the 17 prefecture-level cities in hubei province were selected as the distribution center of cold chain logistics. Find the construction standard of relevant cold chain logistics distribution center and other related parameters as table 2 .

TABLE II OTHER RELEVANT PARAMETERS

\begin{tabular}{|c|c|c|c|c|c|c|}
\hline$a$ & $\varepsilon$ & $\theta$ & $\boldsymbol{v}$ & $\delta$ & $w_{j}$ & $p$ \\
\hline 0.6 & 1500 & 0.0035 & 60 & 2 & 500 & 0.5 \\
\hline
\end{tabular}

\section{A. Results of immune optimization algorithm}

By immune optimization algorithm is used for example, the algorithm of parameter setting are: initial population size of 50, memory inventory to 10 , the number of iterations is 100 , was 0.5 crossover probability, mutation probability is 0.4 , diversity evaluation parameter of 0.95 , use MATLAB to get the following results:

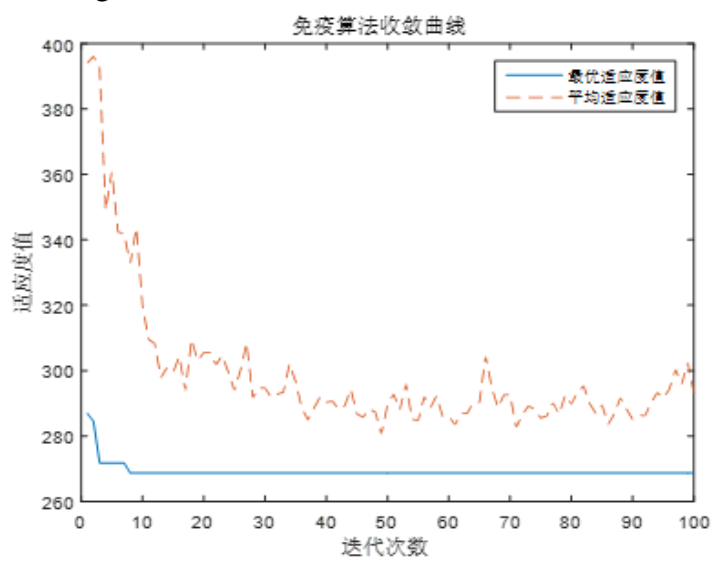

Fig. 3 The convergence curve of immune optimization algorithm

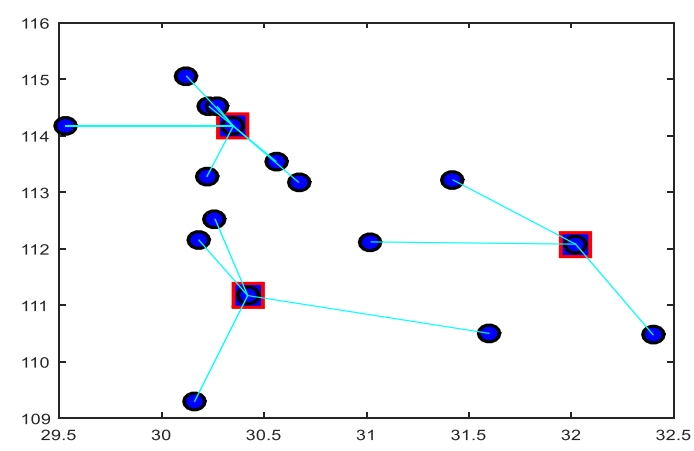

Fig. 4 Location plan of distribution center

According to figure 4. Available in three points with the box says cold-chain logistics distribution center Numbers for the plan of site selection of the best $(1,4,5)$, namely in wuhan, yichang, xiangyang building cold-chain logistics distribution center, to obtain the optimal solution, make the level of total utility is the largest. Wuhan (1) cold chain logistics distribution center in addition to the service of local area, is also responsible for the huangshi(2), (6) of ezhou, xiaogan (8), (10), huanggang xianning (11), (14) of xiantao, tianmen (16), (4) yichang cold-chain logistics distribution center in addition to the service of local area is also responsible for jingzhou (9), enshi (13), qianjiang (15), shennongiia (17), the remaining shiyan (3), jingmen (7), suizhou (12) by xiangyang (5) the cold-chain logistics distribution center service.

\section{CONCLUSION}

"Internet $+"$ the coming of the era, provides new impetus to the development of cold chain logistics, for cold chain logistics distribution center location decision-making of many aspects influence, to achieve a wider range of fresh products circulation, play industry overall scale effect, promote the rapid economic development has played an important role. Under the background of the Internet, from a global perspective, considering the regional demand for products and various cost elements of cold-chain logistics distribution center to determine the optimal location of the cold chain logistics distribution center. Combining immune optimization algorithm, cold-chain logistics distribution center location model is established, through MATLAB simulation merit, choose in 17 cities of hubei province wuhan, yichang, xiangyang as cold-chain logistics distribution center, the radiation from other cities in the province. The size of the three cities, the conditions of transportation, the ability to circulate radiation, the economic level and the natural conditions meet the requirements of the development of logistics distribution center, which is in accordance with objective reality. It is proved that this research model and algorithm have some adaptability and feasibility, which can provide theoretical reference for decision makers in actual decision-making process.

\section{REFERENCES}

[1] Beresnev V L,MelNikov A A . Approximate algorithms for the competitive facilety location problem [J] . Journal of Applied \& Industrial Mathematics,2011,5 (2) : 180-190.

[2] Guanfei, zhang qiang. Fuzzy multi-target logistics distribution center location model and its solution algorithm [J]. China management science, 2013, 21 (zk): 57-62 (In Chinese.)

[3] Ozgen D, Gulsun B. Combining possibilistic linear programming and fuzzy AHP for solving the multi-objective capacitated multi-facility location program [J]. Information Sciences, 2014, 268(6):185-201.

[4] Wei fei. Site selection of fresh food distribution center [D]. Beijing Jiaotong University, 2015.3 (In Chinese).

[5] Yuan qun, zuo yi. Selection optimization of cold chain logistics distribution center based on improved hybrid genetic algorithm [J]. Journal of Shanghai jiaotong university, 2016, 50 (11): 1795-1800 (In Chinese).

[6] Liang haihong. Construction of location optimization model of logistics distribution center in the era of "Internet +" era [J]. Statistics and decision, 2014, 22 (13): 51-53 (In Chinese).

[7] Wang min. Research on the location of cold chain logistics network nodes based on genetic algorithm [D], hunan university, 2010 (In Chinese).

[8] Meng guanghua. Site selection of cold chain logistics distribution center for fresh produce [D], southwest jiaotong university, 2016 (In Chinese).

[9] Zhang jian, fu shaochuan. Study on the location of fresh food distribution center for the influence of freshness [J]. China management science, 2011, 19:473 - 476 (In Chinese).

[10] Ye xiangkui. Site selection of cold chain logistics distribution center [D], Dalian university of technology, 2013 (In Chinese). 